Espaço Aberto | Open Space

\title{
Obituário: Eric Dunning, um pai fundador entre nós
}

\section{Obituary: Eric Dunning, a founding father among us}

\author{
Rod Watson ${ }^{\star}$ \\ * Institut Marcel Mauss - Paris, França \\ r.watson339@btinternet.com \\ https://orcid.org/0000-0001-5858-7850 \\ Édison Luis Gastaldo ${ }^{* \star}$ \\ ${ }^{\star \star}$ Centro de Estudos de Pessoal e Forte Duque de Caxias - Rio de Janeiro, RJ, Brasil \\ edisongastaldo@yahoo.com.br \\ https://orcid.org/0000-0002-4508-0548
}


Eric Dunning, o eminente sociólogo, faleceu em 10 de fevereiro de 2019. Com sua morte, perdemos um - ou melhor, "o" - pioneiro na constituição da sociologia dos esportes como uma área de pesquisa legítima no mundo anglófono. Ele também contribuiu para uma série de outras áreas além da sociologia do lazer e do modo pelo qual as pesquisas sociológicas devem ser conduzidas. Com Norbert Elias, ele desenvolveu uma "sociologia processual" dinâmica.

Eric Geoffrey Dunning nasceu em 27 de dezembro de 1936 em Hayes, na periferia de Londres. Filho de Sidney, um motorista de ônibus e de Daisy (née Morton), uma merendeira escolar. Quando jovem, praticou muitos esportes, tornando-se um talentoso jogador de futebol e críquete. Ele jogou como zagueiro pelo Hayes Athletic, na época um dos principais times amadores da Inglaterra. Ele cursou o ensino superior na Universidade de Leicester, na Inglaterra, mudando de Economia para Sociologia ao ser cativado pelas aulas introdutórias de Norbert Elias. Após sua graduação, Dunning continuou seus estudos com o famoso sociólogo Alvin W. Gouldner, na Universidade Washington, em St. Louis, EUA.

Gouldner teve uma influência em Dunning, mas foi Elias quem continuou sendo seu mentor. Para o resto de sua vida acadêmica altamente prolífica, Dunning desenvolveu temas da obra-prima de Elias, O processo civilizador e trabalhos relacionados com a "sociologia figuracional" do autor. Em seu trabalho sobre o processo civilizador, Elias examinou longos trechos da história e descobriu que, à medida que o tempo passava, as sociedades desenvolviam cada vez mais uma ampla gama de restrições à conduta de seus membros. O estudo das figurações humanas enfatizava os arranjos fluidos, do tipo gestalt, de pessoas interdependentes, às vezes em pequena escala, às vezes em grandes. Dunning adotou essas abordagens gêmeas de análise social e desenvolveu-as criativamente e reespecificou-as ao longo de uma vida acadêmica longa e produtiva. Trabalhou por muitos anos com Elias no Departamento de Sociologia da Universidade de Leicester, que, liderado por Ilya Neustadt, foi então um dos departamentos mais proeminentes da Europa. Um talentoso linguista, Dunning leu o trabalho de Elias diretamente do alemão.

Dunning era modesto sobre o seu trabalho, muitas vezes chamando a si mesmo de "um mero discípulo de Norbert". No entanto, ele era muito mais do que isso, dando-nos uma concepção inovadora do trabalho de Elias e, de fato, da disciplina da sociologia. Sua realização mais notável foi submeter as 
teses gêmeas de "processo civilizador" e das "figurações humanas" a testes conceituais altamente exigentes e a restrições empíricas rigorosas. A área empírica que ele escolheu para esse exercício foi a do esporte, inicialmente do futebol. Isso, por si só, era inovador, pois naquela época (meados dos anos 1960) o esporte não era um dos cânones dos tópicos sociológicos. Elias, que também tinha sido um hábil desportista em sua juventude, prontamente aceitou esta abordagem e depois se juntou a Dunning na busca do estudo figurativo do futebol, em particular ao perceber o desenvolvimento ao longo do tempo de restrições cada vez mais rigorosas e complexas na conduta dos jogadores e espectadores. A área do esporte até então não tinha sido vista pelos sociólogos como suficientemente significativa para merecer atenção analítica, e Dunning foi pioneiro no estudo do esporte como um tópico sociológico legítimo e importante. Por sua atuação direta, estabeleceu-se um grupo de sociólogos "eliasianos" em Leicester, todos trabalhando com a sociologia dos esportes. Esse grupo viria a tornar-se conhecido como a Escola de Leicester da sociologia do esporte e, sob essa égide, aqueles sociólogos individuais tornaram-se autores renomados. Um dos alunos de Dunning, Jason Hughes, colaborou com ele na coautoria do que muitos consideram ser o texto mais importante sobre a obra de Elias, Norbert Elias and modern sociology - "Norbert Elias e a sociologia moderna", inédito em português (Dunning; Hughes, 2013).

Entretanto, descrever Eric Dunning apenas como "pioneiro da sociologia dos esportes" ainda seria pouco. Ele era teórico da sociologia altamente sofisticado, e estava na posição adequada para reespecificar algumas das discussões de Elias. Além disso, Dunning abordou muitos outros temas além do esporte em sua obra. Por exemplo, questões de autonomia e reciprocidade (um dos temas favoritos de Gouldner), debates sobre o historicismo de Popper e vários tópicos sobre mudança social, baseados em suas leituras de Comte e Durkheim no idioma original. Ele foi reconhecido por sua leitura crítica da tese da "convergência estrutural", desenvolvida por Clark Kerr et al. nos EUA e seguida por John Goldthorpe na Inglaterra. Juntamente com seu colega Earl Hopper, Dunning entrou em um debate impresso com Goldthorpe, esclarecendo vários pontos obscuros naquela teoria. Dunning também ministrou cursos sobre relações étnicas e raciais e escreveu em termos eliasianos sobre holocaustos e genocídios: seus interesses acadêmicos não se resumiam ao futebol. 
Com Elias, Dunning também desafiou alguns dos conceitos mais acalentados da ortodoxia sociológica, como as oposições binárias entre "indivíduo x sociedade", "agressão x controle", "concreto x abstrato", "self x outro". Eles também atacaram as formulações mentalistas e cognitivistas na sociologia e na psicologia. Assim, prefiguraram a reespecificação radical que seria feita mais tarde por outras formas de sociologia, como a etnometodologia. A reespecificação total desta disciplina intelectualmente conservadora - a ciência social - continua a ser uma tarefa por concluir. No entanto, permanece o fato de que Dunning realizou grandes avanços na teoria sociológica geral.

Em busca de seus objetivos acadêmicos, Dunning foi extraordinariamente prolífico. Seu livro escrito em coautoria com seu colega K. Sheard, Barbarians, gentlemen and players - "Bárbaros, cavalheiros e jogadores", inédito em língua portuguesa (Dunning; Sheard, 2005) - é considerado a melhor análise sociológica diacrônica já publicada sobre um esporte (no caso, o rugby). Seu livro em coautoria com Elias, Quest for excitement, publicado pela DIFEL, em Portugal com o nome A busca da excitação (Elias; Dunning, 1992) examina o modo pelo qual a prática de esportes modernos e sua espetacularização forneceram um quadro institucional para a produção da emoção coletiva sentida em formas primitivas e menos reguladas de jogo. A partir de acurada pesquisa histórica, Dunning percebeu que as primeiras manifestações do jogo que viríamos a chamar de futebol era pouco mais do que uma rixa entre aldeias. Violência e agressões eram a tônica nesses eventos. Assim, parte do crescente controle social sobre os esportes estava a serviço de conter as paixões que levavam à violência - aquilo a que Goffman (1967) chama de "ação" em seu célebre ensaio "Where the action is". Quando um dos autores deste tributo, Rod Watson, conheceu Erving Goffman, este se mostrou muito interessado na sociologia de Elias, que conhecia bem. $\mathrm{O}$ "processo civilizador" frequentemente resultava em contenção institucional da agressão, nunca sendo possível extirpá-la completamente. Com este argumento, Dunning tornou-se um expert internacional sobre o hooliganismo, tendo aparecido muitas vezes no rádio, televisão e imprensa de todo o mundo. Sua capacidade de dizer coisas complexas de maneira simples ajudou muito, a ele e a seu público.

Rod Watson foi aluno de Elias e de Dunning, na graduação e na pós-graduação. Ele considerava que nas aulas de Dunning não havia pretensão ou presunção, e suas ideias eram expressas de maneira incomumente clara - isso em um 
tempo em que "clareza" não era o forte e nem mesmo o objetivo de muitos cientistas sociais... Os estudantes ouviam sua exposição lúcida, muitas vezes apresentada de modo leve e humorado (ele tinha um senso de humor rabelaisiano de que os estudantes gostavam muito e que mantinha sua atenção). No final, ficava em todos a sensação de que tinham aprendido um argumento profundo e sofisticado de modo indolor. Eric Dunning teve uma relação longa e intensa com o Brasil, país onde sua obra é muito conhecida e citada. Nas diversas vezes em que esteve aqui, fez um grande número de amigos e admiradores.

\section{Eric Dunning no Brasil}

Eric Dunning esteve pelo menos oito vezes no Brasil, entre 1996 e 2011 (Reis, 2014). Seu primeiro contato com o universo da pesquisa brasileira sobre sociologia dos esportes ocorreu em um congresso em Portugal, em 1996, quando a professora Maria Beatriz Rocha Ferreira o conheceu pessoalmente. Naquele mesmo ano, ele foi convidado para participar como conferencista do I Simpósio Internacional Norbert Elias, realizado na Faculdade de Educação Física da Unicamp.

Foi uma aluna de Maria Beatriz, a professora Heloisa Helena Baldy dos Reis, que se tornaria a principal interlocutora de Dunning no Brasil. Uma das mais destacadas estudiosas do hooliganismo e das políticas públicas sobre violência entre torcedores no Brasil, Heloisa encontrou muitas convergências entre seu trabalho de pesquisa e a obra de Elias e Dunning. Assim, ela esteve diretamente envolvida no desenvolvimento teórico da obra de Dunning no Brasil nos últimos 20 anos, convidando-o a participar de palestras, entrevistas e outras atividades acadêmicas. A mais longa estada de Dunning no Brasil ocorreu em maio de 2011, quando permaneceu por duas semanas ministrando palestras e conferências, atendendo estudantes e jovens pesquisadores e participando de programas de rádio e televisão (Dunning, 2014).

Um dos autores deste tributo, Édison Gastaldo, havia conhecido o prof. Dunning pessoalmente, em um encontro de pesquisadores ocorrido na Universidade de Staffordshire, em Stoke-on-Trent, na Inglaterra. Na ocasião, ele era professor visitante na Universidade de Manchester, e foi ao evento acompanhado do outro autor, Rod Watson, colega e amigo de longa data de Dunning. 
Ele havia recentemente recebido um prêmio internacional por seu livro Sport matters (Dunning, 1999), e havia muitos jornalistas cobrindo a conferência. Não obstante, ele foi muito gentil e simpático, em uma generosa conversa ao final do evento. Alguns anos mais tarde, Gastaldo foi convidado pelo prof. Arlei Damo para publicar uma entrevista com Eric Dunning, para o número especial da revista Horizontes Antropológicos dedicada à antropologia do esporte. Eric foi contatado por e-mail, com o convite para a entrevista. Ele aceitou prontamente. Realizada por e-mail, com uma pergunta a cada mensagem, ao longo de um mês, a entrevista foi publicada em 2008, e está disponível on-line (cf. Gastaldo, 2008).

A entrevista foi muito bem recebida, e é bastante acessada ainda hoje. Por conta dela, Heloisa Reis convidou Gastaldo, em 2011, a participar, como tradutor e comentarista, da visita que Dunning faria à Unicamp naquele ano. Foi quando teve a oportunidade de conviver mais diretamente com o prof. Dunning. Por vários dias, Gastaldo o seguiu em seu extenso roteiro de atividades acadêmicas. Entre as produções acadêmicas decorrentes dessa visita, está o livro Sociologia do esporte e os processos civilizatórios (Dunning, 2014) (organizado por Heloisa Reis e publicado pela Annablume em 2014), único livro autoral de Dunning publicado no Brasil até hoje.

A energia, bom humor, generosidade e simpatia do prof. Dunning conquistaram a todos. Sua reputação internacional de "pai fundador" da sociologia dos esportes não o impedia de sentar entre estudantes de graduação em uma mesa de café, e ouvir atentamente, discutir e dar sugestões de pesquisa para eles. Sua formação como atleta de críquete e futebol na juventude deve ter lhe deixado esta marca de jovialidade e espírito aberto. Após as palestras e atividades acadêmicas, ele sempre fazia questão de convidar a todos para irem com ele a um bar, onde as questões teóricas se prolongavam entre cervejas e risadas, até tarde da noite. Ele gostava muito dessa sociabilidade com os jovens, e sempre contava muitas histórias engraçadas. Os estudantes, por sua vez, apesar de jovens, precisavam fazer revezamento para acompanhar o prof. Dunning em sua maratona de dias e noitadas! Em um churrasco em sua homenagem, na casa da prof. Heloisa, ele vangloriou-se de jamais ter perdido uma beer race em toda sua vida ("corrida da cerveja", uma brincadeira de bar conhecida como "vira-vira" no Brasil: ganha quem beber um caneco de cerveja primeiro e bater o caneco vazio na mesa). Então, desafiou quem quisesse competir com ele. Como ninguém se voluntariou, Gastaldo aceitou o desafio, para participar da 
brincadeira: a competição em si não teve graça, pois antes que seu caneco chegasse à metade, Dunning havia batido o dele na mesa, para aplauso de todos. Invencibilidade mantida.

Daqueles dias, Gastaldo destaca a lembrança da convivência com um gigante gentil. Sempre espirituoso, simples e disposto a ajudar, Eric Dunning ensinou muito mais do que a relação do esporte com o processo civilizatório: ensinou a todos como ter grandeza sem arrogância, e como ser denso e profundo sem perder a simplicidade e a generosidade. Em tempos de hostilidade, rancor e intolerância com as diferenças, um exemplo a ser seguido.

Eric Dunning deixou um filho, Michael, uma filha, Rachel, dois netos e seu irmão Roy.

\section{Referências}

DUNNING, E. Sport matters. London: Routledge, 1999.

DUNNING, E. Sociologia do esporte e processos civilizatórios. São Paulo: Annablume, 2014.

DUNNING, E.; HUGHES, J. Norbert Elias and modern sociology. London: Bloomsbury, 2013.

DUNNING, E.; SHEARD, K. Barbarians, gentlemen and players. London: Psychology Press, 2005.

ELIAS, N.; DUNNING, E. A busca da excitação. Lisboa: DIFEL, 1992.

GASTALDO, E. Esporte, violência e civilização: uma entrevista com Eric Dunning. Horizontes Antropológicos, Porto Alegre, ano 14, n. 30, p. 223-231, jul./dez. 2008. Disponível em: http://www.scielo.br/pdf/ha/v14n30/a09v1430.pdf. Acesso em: 1 jul. 2019.

GOFFMAN, E. Where the action is. In: GOFFMAN, E. Interaction ritual: essays on face-to-face behavior. New York: Doubleday, 1967. p. 149-270.

REIS, H. H. B. As contribuições de Eric Dunning para o desenvolvimento da sociologia do esporte no Brasil: uma introdução à sociologia figuracional. In: DUNNING, E. Sociologia do esporte e processos civilizatórios. São Paulo: Annablume, 2014. p. 7-13. 